\title{
Reduced Gravity Testing of the Nanoparticle Field Extraction Thruster
}

\author{
Steven Morris ${ }^{1}$, Brittany Drenkow ${ }^{2}$, Thomas Liu ${ }^{3}$, Theresa Biehle ${ }^{4}$, Joseph Munski ${ }^{5}$, Horim Han $^{6}$, Kurt Swieringa $^{7}$, \\ Patrick Martinchek ${ }^{8}$, Michelle Knapp ${ }^{9}$, Rachel Trabert ${ }^{10}$, Rebecca Wind ${ }^{11}$, Benjamin Brierty ${ }^{12}$, Brian Gilchrist ${ }^{13}$, and \\ Alec Gallimore ${ }^{14}$ \\ University of Michigan, Ann Arbor, MI 48109
}

\begin{abstract}
During the 2006-2007 and 2007-2008 academic calendar years, C-9 NanoBLUE, a team of undergraduates within the University of Michigan's Student Space Systems Fabrication Laboratory, investigated the effects of a reduced gravity environment on the Nanoparticle Field Extraction Thruster concept. This investigation was completed through the NASA Reduced Gravity Student Flight Opportunities Program at NASA Johnson Space Center. This paper focuses on the design-build-test-fly activities associated with project.
\end{abstract}

\section{Introduction}

$\mathrm{T}^{1}$ he C-9 NanoBLUE team is a group of students within the University of Michigan's Student Space Systems Fabrication Laboratory (S3FL) seeking hands-on undergraduate research experience. The focus of the project is the reduced gravity (microgravity) test and validation of the concept for the Nanoparticle Field Extraction Thruster (NanoFET), an electric propulsion system being developed at the University of Michigan. These microgravity tests were done as part of the NASA Reduced Gravity Student Flight Opportunities Program at NASA Johnson Space Center. Over the course of the 2007-2008 time period, the team followed S3FL's educational methods and built upon the design and results of the previous year's C-9 NanoBLUE team to provide useful flight data.

The Student Space Systems Fabrication Laboratory is a student-run laboratory where members learn from and teach each other along with faculty and industry support. The overall goal of this organization is to provide undergraduate students the opportunity to gain hands-on research and engineering experience through real-world projects related to space systems. This goal is accomplished via the design-build-test-fly philosophy employed by each team. Each project consists of team members who take part in the application, team leads who direct tasks and coordinate the overall project, and Executive Committee members who oversee progress and assess results produced by the team. Each of these positions consists only of students within the organization. Newer members start off as team members on a project where they can work their way up to lead and mentorship positions once they demonstrate the requisite technical and leadership skills. From a lead position, a member can eventually move up to the Executive Committee where he/she can assist various teams and direct activities throughout the lab. With this structure, students who participate are able to gain valuable experience in different aspects of the aerospace industry. ${ }^{1}$

\footnotetext{
${ }^{1}$ Undergraduate Student, Aerospace Engineering, sbmorris@umich.edu, AIAA Student Member

${ }^{2}$ Undergraduate Student, Aerospace Engineering, bdrenkow@umich.edu, AIAA Student Member

${ }^{3}$ Graduate Student, Aerospace Engineering, liutm@umich.edu, AIAA Student Member

${ }^{4}$ Undergraduate Student, Aerospace Engineering, biehlet@umich.edu

${ }^{5}$ Undergraduate Student, Aerospace Engineering, munskij@umich.edu

${ }^{6}$ Graduate Student, Aerospace Engineering, mrhan@umich.edu

${ }^{7}$ Undergraduate Student, Aerospace Engineering, kswier@umich.edu

${ }^{8}$ Undergraduate Student, Aerospace Engineering, pmchek@umich.edu

${ }^{9}$ Undergraduate Student, Chemical Engineering, mlknapp@umich.edu

${ }^{10}$ Undergraduate Student, Aerospace Engineering, raetr@umich.edu

${ }^{11}$ Undergraduate Student, Aerospace Engineering, rjwind@umich.edu

${ }^{12}$ Undergraduate Student, Aerospace Engineering, bbrierty@umich.edu

${ }^{13}$ Professor, Electrical Engineering \& Space Systems, gilchrst@umich.edu, AIAA Associate Fellow

${ }^{14}$ Arthur F. Thurnau Professor, Aerospace Engineering \& Applied Physics, rasta@umich.edu, AIAA Associate Fellow
} 
The C-9 microgravity program has been an excellent opportunity for fulfilling several of S3FL's educational and engineering objectives. NASA's Reduced Gravity Program at the Johnson Space Center gives college undergraduates a chance to get hands-on experience in the fields of science and engineering through flying a scientifically significant experiment on their C-9B aircraft. The aircraft flies in parabolas over the Gulf of Mexico that produces about $20 \mathrm{~s}$ of microgravity per parabola. During the ascent period of each parabola, aircraft occupants experience a force 1.8 times normal gravity. During the descent period of each parabola, the occupants are approximately weightless. Students demonstrate the validity of their experiment to the program through an initial proposal. After proposal acceptance, experiment flight readiness is demonstrated through design and analysis documentation called the Test Equipment Data Package (TEDP). Ultimately, the team completes a safety and readiness inspection the week of their flight with NASA safety officials. After a team has flown their two flights on the C-9B aircraft, they submit a final report to NASA with the results produced from their experiment. For the past two years, this program has served as an important testing platform for the NanoFET concept as it provides a reasonably accessible space analogue testing environment for the space thruster technology under development. ${ }^{2}$

NanoFET's operation is dependent upon the electrostatic charging and acceleration of spherical micro/nanoparticles from a liquid reservoir to create high efficiency thrust for spacecraft applications. ${ }^{3}$ A main concern of this project is the effect of reduced gravity conditions on the liquid transport system responsible for moving particles into the thruster's extraction channels. In ground testing, the phenomenon of Taylor cone formation will occur in a given liquid once a certain electric field threshold is reached. This liquid instability event occurs when the electric field force at a given point on the liquid surface becomes comparable to the gravity and surface tension forces holding the liquid down. ${ }^{4}$ This event is depicted in Figure 1. This event occurs even more readily in

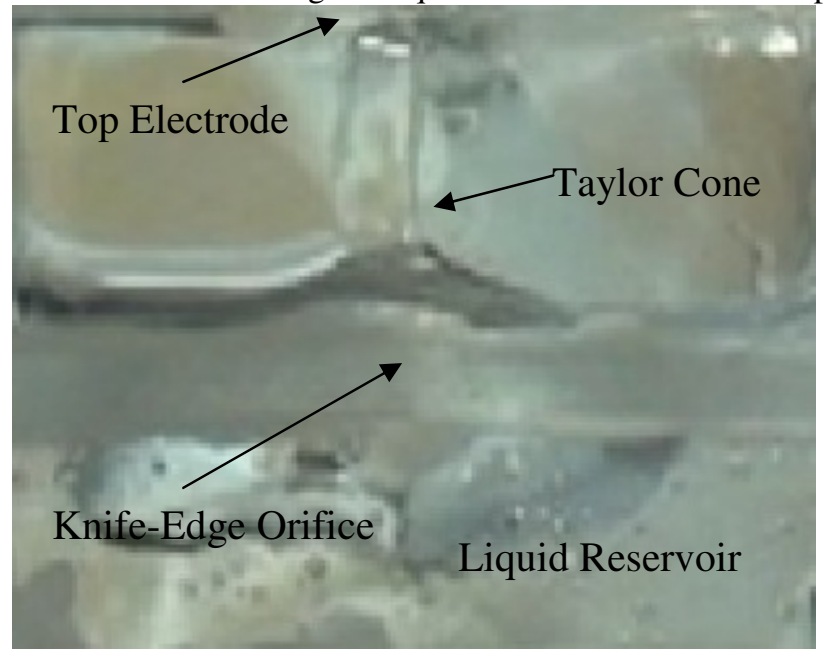

Figure 1. Taylor cone formation. This liquid instability was formed during a test of the 2006-2007 experiment.

the microgravity environment where the gravitational force holding the liquid down is removed. The onset of liquid surface instabilities prior to particle extraction causes non-ideal performance in NanoFET and thus must be investigated to facilitate the development of engineering controls. Furthermore, it must be conclusively shown that the micro/nanoparticles can be successfully extracted from a liquid reservoir before this liquid instability occurs. Since this system will operate in space, it is necessary to understand how removing the major gravitational forces will affect the liquid dynamics of the system as well as the ability to extract and accelerate particles. Alternatively, a non-liquid configuration of NanoFET is also being developed, and its concept must also be demonstrated in a microgravity environment. ${ }^{5}$

The C-9 NanoBLUE team thus set out over the course of the 2006-2007 and 2007-2008 academic years to prove that the NanoFET concept is feasible in a microgravity environment, a necessary step in developing it into a thruster that could be used on future space missions. This paper will mainly focus on the second experiment from 2007-2008. The main objectives of the 2006-2007 experiment were to 1) determine the threshold electric field for liquid surface instability and Taylor cone formation as a function of liquid depth and liquid reservoir span (characteristic length scales) in microgravity and 2) demonstrate the ability to extract millimeter-sized particles from liquid reservoirs. During each flight day, the team conducted one of these two experiment types per parabola. This allowed the team to collect data from both experiments each day so that an inability to test on one flight did not result in the complete loss of a data set. Both tests were used to observe the interaction between the liquid and container walls in microgravity. The team successfully observed liquid instability formation but was not able to achieve particle extraction due to flaws in the test cell design. The results gained from this initial experiment were used to help the team understand the C-9B test environment, gain insights to design improvements, and plan for more rigorous follow-on studies. ${ }^{6}$ Figure 2 shows a picture of the final assembled experiment that was flown in May 2007.

Several lessons were learned from the 2006-2007 experiment that were to help improve the 2007-2008 experiment. The first and most important lesson being that whatever experiment was designed should be able to be run by one person as previous flight crew members had become sick on the microgravity flight. Furthermore, analysis of the previous flight data, current Taylor cone formation theory, and Paschen curve regarding the 
breakdown point of air onboard the aircraft changed the design of the liquid instability cells for the newer experiment. This would allow for more successful collection of data points at which Taylor cones would form in flight without as great a risk of causing electrical arcing to occur during the tests. Also, it was agreed upon that automating portions of the newer experiment would improve the data collection process as flight crew members could focus on the behavior of the system in flight rather than several different procedural steps for each test. This led to the development of a LabVIEW code used to automate portions of the newer experiment and automatically record data points to later compare with video taken in flight. This method greatly helped to confirm more data points and lower the amount of error on the overall experiment. Lastly, the new experiment set out to characterize the variations in the behaviors of liquid instability and particle extraction with different geometry knife-edge orifices. The knife-edge orifice, used to hold liquid in place during microrgravity, is discussed in sections II and III.

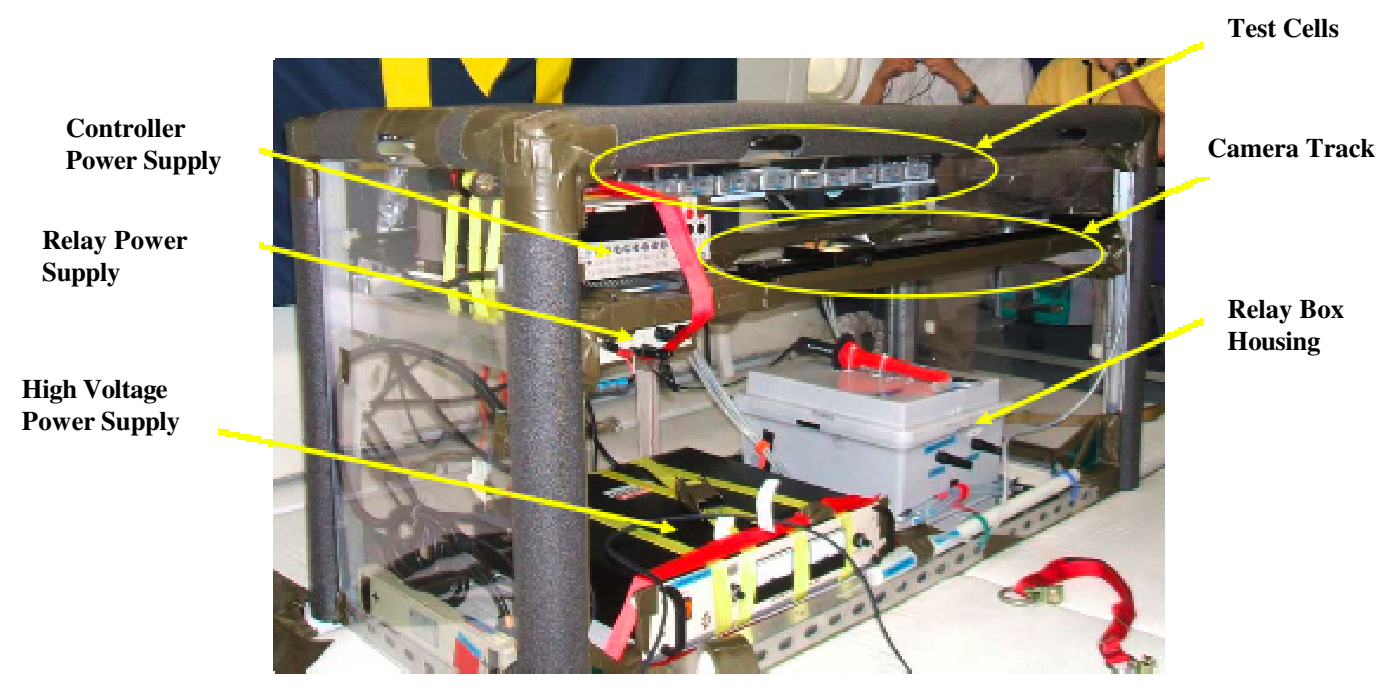

Figure 2. 2006-2007 Integrated Experiment Structure. All experiment components shown with the exception of flight camera not present on camera track.

\section{Design of 2007-2008 Reduced Gravity Experiment}

The design of the 2008 microgravity experiment began in the Fall of 2007. The design of the new experiment focused on gaining further insight into liquid instability formations in NanoFET through the implementation of various knife-edge orifice geometries, which were successfully demonstrated in the 2006-2007 flights, to hold down liquid in a reservoir during microgravity. Completing the proof-of-concept particle extraction tests that were not completed in the previous experiment was also of priority. Furthermore, the new design was focused on fixing many of the faults identified on the previous experiment and streamlining operations by automating large portions of the experiment.

The new team was divided up amongst five subsystem teams: structures, power and electrical/ command and data handling, payload, systems, and outreach. The last of these teams was responsible for the fulfillment of NASA's requirements for each microgravity team to perform outreach events with local K-12 schools to help stimulate the growth of future engineers and scientists. Weekly meetings between the subsystem leads encouraged crosssubsystem communication and allowed team members to update one another on the progress of overall team goals and schedules. The team's structure can be seen in Figure 3. The principal investigator role, who was responsible for finalizing the team's science objectives, was fulfilled by University of Michigan researchers involved in NanoFET's development. An in-depth discussion of the outreach team can be found within section V. 




Figure 3. Breakdown of C-9 NanoBLUE subsystem teams. Each subsystem team was led by a subsystem lead who would interact with the team lead and principal investigator.

Throughout the year, three major design reviews were held. The first was a Mission Definition Review (MDR) that was held near the end of the first semester in December. This review's main purpose was to present the preliminary project objectives and design to reviewers who could help improve the design early on. The second review was a Critical Design Review (CDR) that was held during the middle of the second semester in February. Its main purpose was to present the team's final design to reviewers and allow them to flag any final issues with the design before intensive fabrication began. Finally, a Go/No-Go Review at the end of the second semester in April was held to prove the functionality of the design to outside reviewers and to convince them of the project's flight readiness.

\section{A. Structural Design}

The structures subsystem handled the design and manufacturing of all test equipment with the exception of electronic circuits. Design and manufacturing of flight hardware required the full cooperation of structures team members along with the payload and power and electrical subsystems. The structures team brainstormed with the payload team in order to produce test cells that addressed issues encountered last year, including the non-uniformity of applied electric fields, inability to clearly obtain a top view of the liquid surface during instability events, and difficulty in maintaining particle contact to charging electrodes. A process of drafting, prototyping, and re-designing took place for multiple months before full production of the units was initiated following CDR. The power and electrical subsystem produced a number of hardware designs, exemplified by a pin-switch power distribution system (discussed in section III), which the structures subsystem fully developed. The manufacturing and prototyping tasks were accomplished in-house by a subset machining group of the structures team using basic manufacturing tools such as manual end mills and lathes at the University of Michigan's Wilson Student Team Project Center. Additionally, all stock material and pre-fabricated items underwent trade studies and special selection processes by the structures team. The structural frame, inherited from last year's flight, was updated to provide an ergonomical layout and facilitate experiment operations. Members of the structures subsystem used computer-aided finite element analysis (FEA) along with computer-aided drafting (CAD) tools to satisfy all design concerns of the frame.

FEA was conducted on the experiment chassis holding all experimental components. In order to meet NASA's requirements, analysis had to verify that the system could withstand loads ranging up to 9 times normal gravity. The team employed Abaqus to conduct the analysis, with the loads on each beam summed together and placed at the centroid of the beam. A sample output of this analysis is seen in Figure 4. For additional security, a factor of safety of at least two was placed on all of the components. In order to verify success in meeting all necessary requirements, the structure had to meet each test condition without allowing the maximum stress to meet the unistrut aluminum bars' yield point. Construction of the experiment chassis is discussed in section III. 


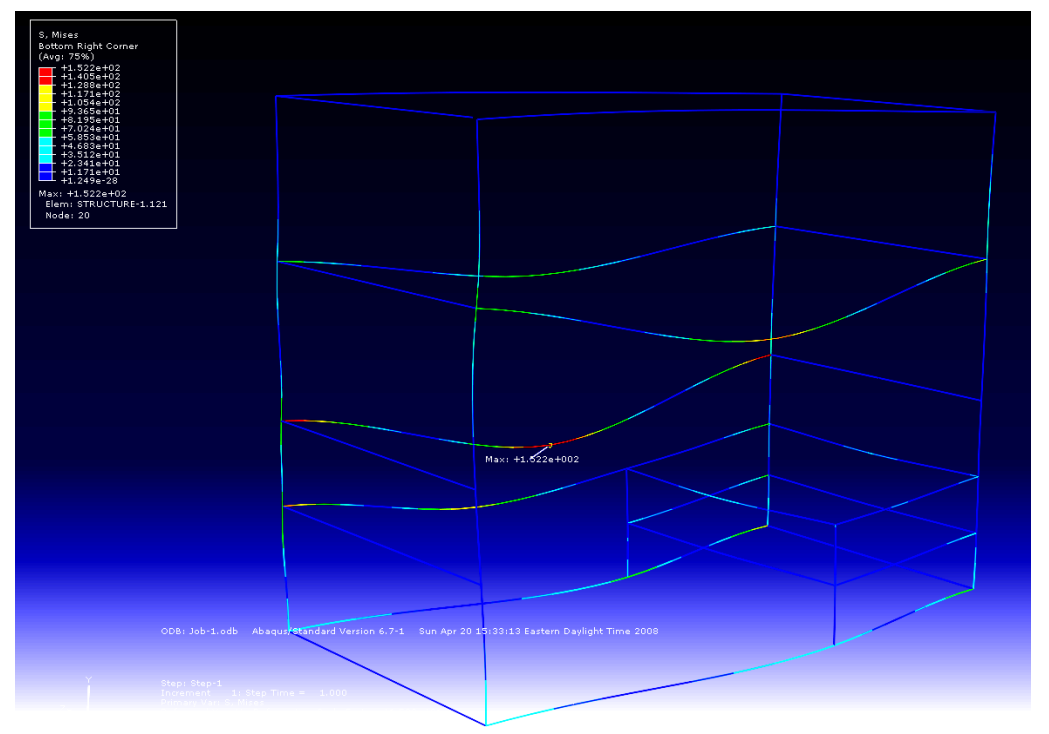

Figure 4. A sample FEA of the experiment chassis with a downward pointing load. The color scheme of the figure depicts stress concentrations with red areas being high stress and blue areas being low stress.

\section{B. Power and Electrical Design}

The main objective of the power and electrical system was to meet the power needs of the experiment while complying with safety requirements set by NASA. The system was divided into high-voltage, low-voltage, and control signal voltage layers. The function of the high-voltage subsystem was to generate, distribute, and measure the voltage applied to each test cell. Designed to handle voltages up to $30 \mathrm{kV}$, the system consisted of a Glassman high-voltage power supply, a voltmeter (multimeter) with a high-voltage probe, a power distribution box, a discharger, and a high-voltage relay. The low-voltage subsystem consisted of a DC power supply, several DC lowvoltage relays, and several solenoids within the power distribution interface. It allowed the operators to change the routing of the high-voltage connections to different test cells or to the discharger (via either the experiment automation software or a redundant manual switch interface). This design is depicted below in Figure 5.

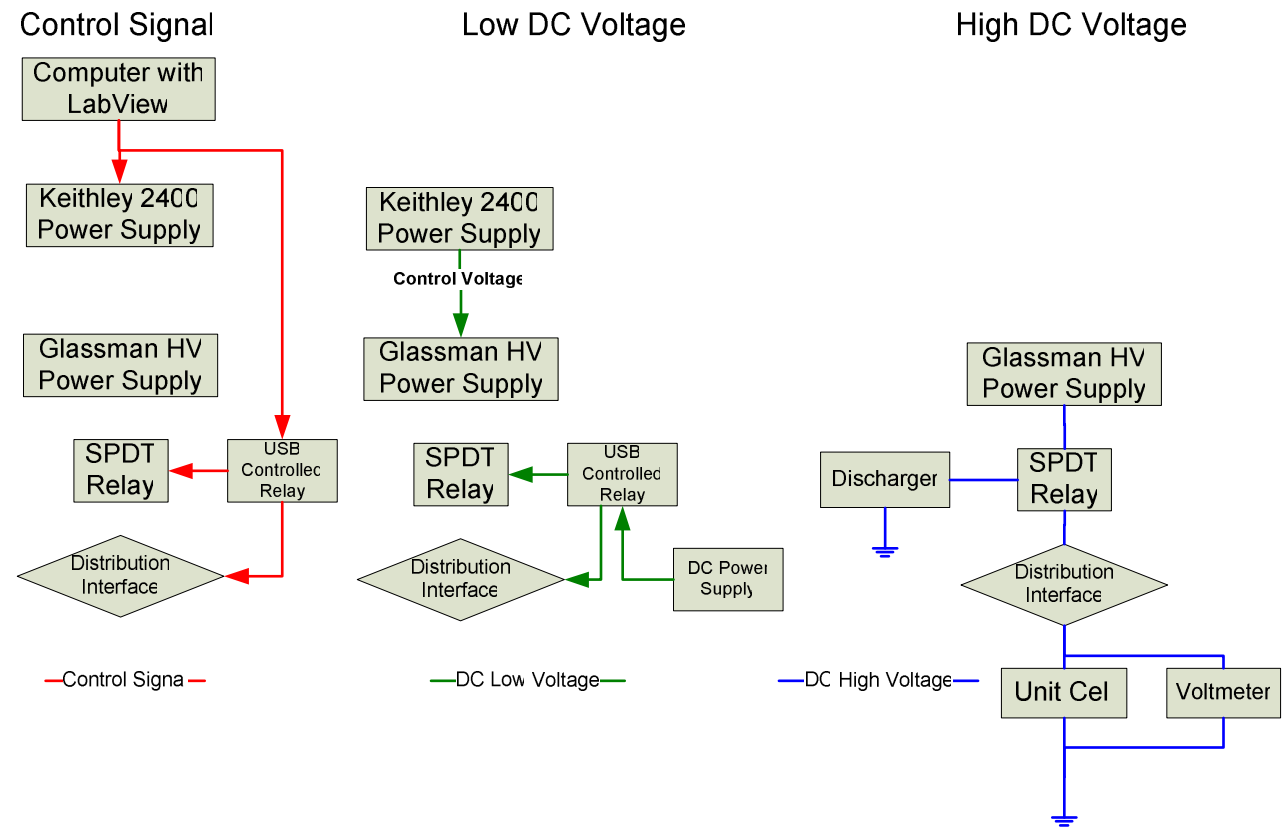

Figure 5. Electrical systems design. The control signal, low voltage and high voltage lines are shown separately for clarity. 


\section{Payload Design}

The purpose of the payload subsystem was to validate each portion of the experiment hardware and procedures through analysis and testing to ensure readiness for flight. This included safety reviews of materials and development of various standardized processes used in ground testing and in flight. The main focus of the payload subsystem was qualification and acceptance tests of the particle extraction and liquid instability test cells. This included internal and external leak testing, electrical continuity, and functionality testing of the cells. These tests drove the fabrication processes of the structures and electrical teams as they demonstrated improvements to be made within the designs. The payload team was also responsible for helping interpret the ground and flight test data to show how it correlated with current models for the NanoFET system.

\section{Systems Design}

The purpose of the systems subsystem was to ensure that all the subsystems were communicating successfully with each other. Furthermore, this subsystem managed the team's action items, requirements compliance matrix, and overall schedule. The systems team was also responsible for organizing design reviews that corresponded with important milestones in the design, fabrication, and test processes. Towards the end of the year, the systems team organized Concurrent Design Meetings (CDMs) in order to facilitate discussion of cross-subsystem design issues with the entirety of the team and promote team member participation in the overall design process.

Lastly, the systems team ran simulations of different test cell configurations in COMSOL, a commercial multiphysics package, to ensure that the experiment was feasible with the parameters that had been given. These simulations were run continually throughout the year as the experiment design evolved to ensure that the strength of the electric fields present were large enough to encourage liquid instability but small enough not to break down the air gap in the test cells and cause electrical arcing. These simulations were run on configurations after the design phase and were communicated to the structures team before machining began.

\section{E. Integrated Systems Design}

The NanoBLUE integrated experiment structure is as shown in Figure 6. The experiment includes an array of 10 test cells ( 3 particle extraction cells and 7 liquid instability cells), a high-voltage box, a pin-switch power distribution mechanism, pin-switch manual control box, a camera mount, a flight laptop computer, a data acquisition box (DAQ), a high-voltage control power supply (Keithley sourcemeter), BK Precision low-voltage power supply (DC Power Supply), and a Glassman high-voltage power supply (HVPS). The unit cell array is situated in the upper portion of the chassis, and the in-house-built high-voltage pin-switch mechanism is directly below the array and wired directly between the cells and the high-voltage box. Once the high-voltage relay and pin-switch mechanism are engaged, the computer sends a signal to the Keithley sourcemeter, which in turn sends signals to raise the Glassman power supply's voltage in specified increments from $8 \mathrm{kV}$ to $24 \mathrm{kV}$. The Glassman sends high-voltage through the high-voltage box containing the relay to the pin-switch mechanism and then up to the associated cell. Cameras on the top and front of each cell record events while voltage and current from the Glassman and Keithley power supplies along with the flight accelerometer data are recorded on the DAQ. LED lights placed next to each cell channel allow the DAQ data and video data to be synchronized together for post-flight analysis.

The integrated systems design evolved as further testing was done. As more tests were conducted and more knowledge was gained about the experiment by the team, it was seen that some of the initial designs such as lighting devices and component placements would have to be changed. Thus, by starting these tests early many problems were solved while they were still manageable. Each member of the flight crew was required to be present at a minimum number of these integrated systems to have input on the final integrated design. By doing this, every flight crew member was very comfortable with experiment system before flight. Further discussion of integrated systems testing and development can be found in section III. 


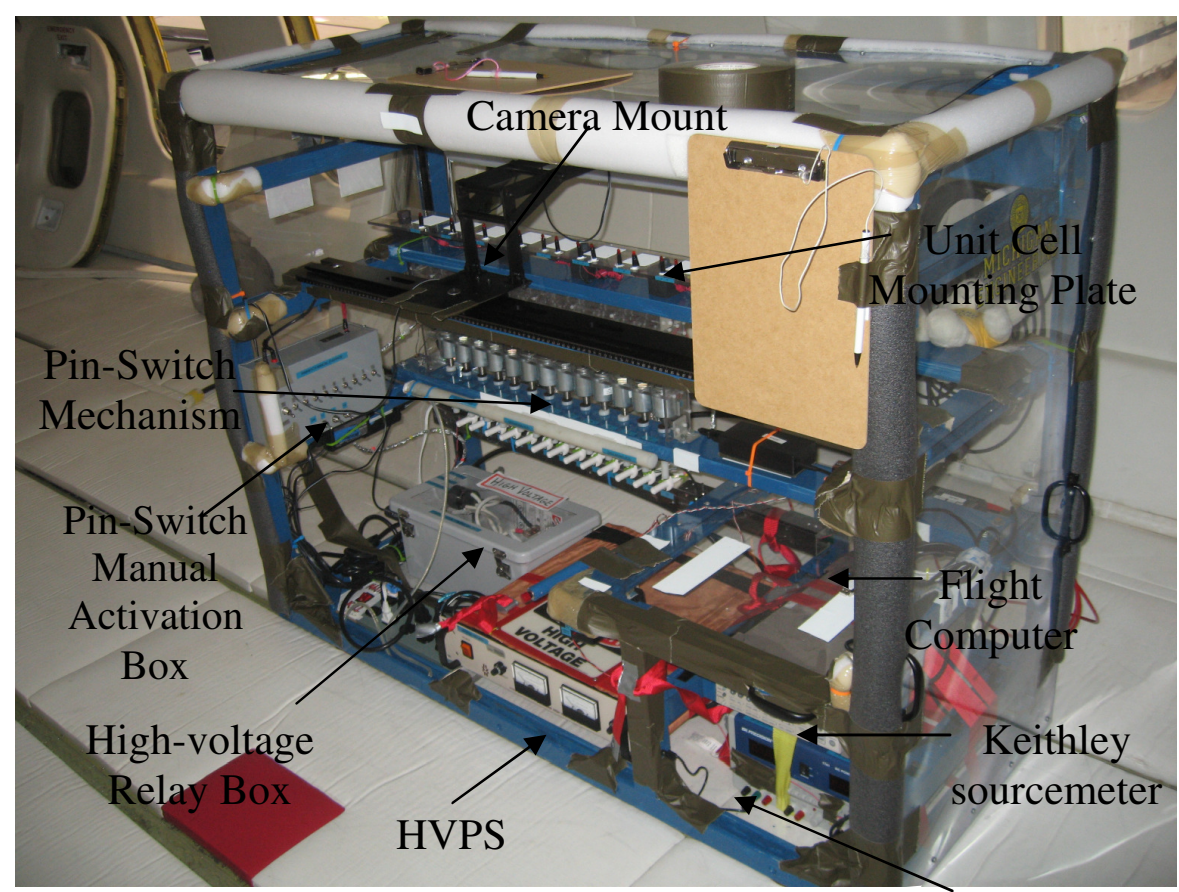

Figure 6. 2007-2008 Experiment integrated system design onboard the C-9B aircraft. The flight computer and test cell locations are shown, but the components themselves are not present. The DAQ cannot be seen from this angle.

\section{Fabrication and Testing of Experiment}

As a method of improving upon the results of the previous year's experiment, a strong emphasis was placed on beginning fabrication and testing of experiment components early to have a better developed integrated experiment for the flight as well as to better understand what was needed to ensure sufficient data collection for post-flight analysis.

\section{A. Structural Systems}

The structures team was placed in charge of fabricating particle extraction and liquid instability test cells along with the high-voltage pin-switch mechanism. Each of these tasks is discussed at length within this section. Lastly, the structures team designed and constructed the experiment chassis in which all experiment components were housed.

One of team NanoBLUE's main objectives for the 2007-2008 project was to demonstrate millimeter-sized particle extraction that could be readily visible from both liquid-less and liquid-filled containers. These test cells were designed and built out of polycarbonate rods. In these particle extraction cells, there were three high-aspect ratio charging pads each making contact with a single aluminum sphere. At the top of each particle extraction cell was a conductive ITO (indium tin oxide) glass slide electrode allowing for a clear view into the cell from above. One-third of the way from the bottom of the reservoir was a knife-edge orifice used to pin down liquid in microgravity. This knife-edge orifice suppresses the capillary forces on a liquid in the microgravity environment, which keeps the liquid from climbing the test cell walls. ${ }^{7}$ Two-thirds of the way up from the bottom of the reservoir was an accelerating grid machined of stainless steel in the same configuration as the knife-edge; this grid was kept electrically grounded along with the ITO electrode. During the two flights, three different knife-edge configurations were tested, including one large circular orifice surrounding all three charging pads, three small circular orifices (one for each charging post), and a slot-shaped orifice surrounding all three charging pads but aligned parallel to the front of the unit cell. Figure 7 depicts top and side views of the particle extraction cell design. 


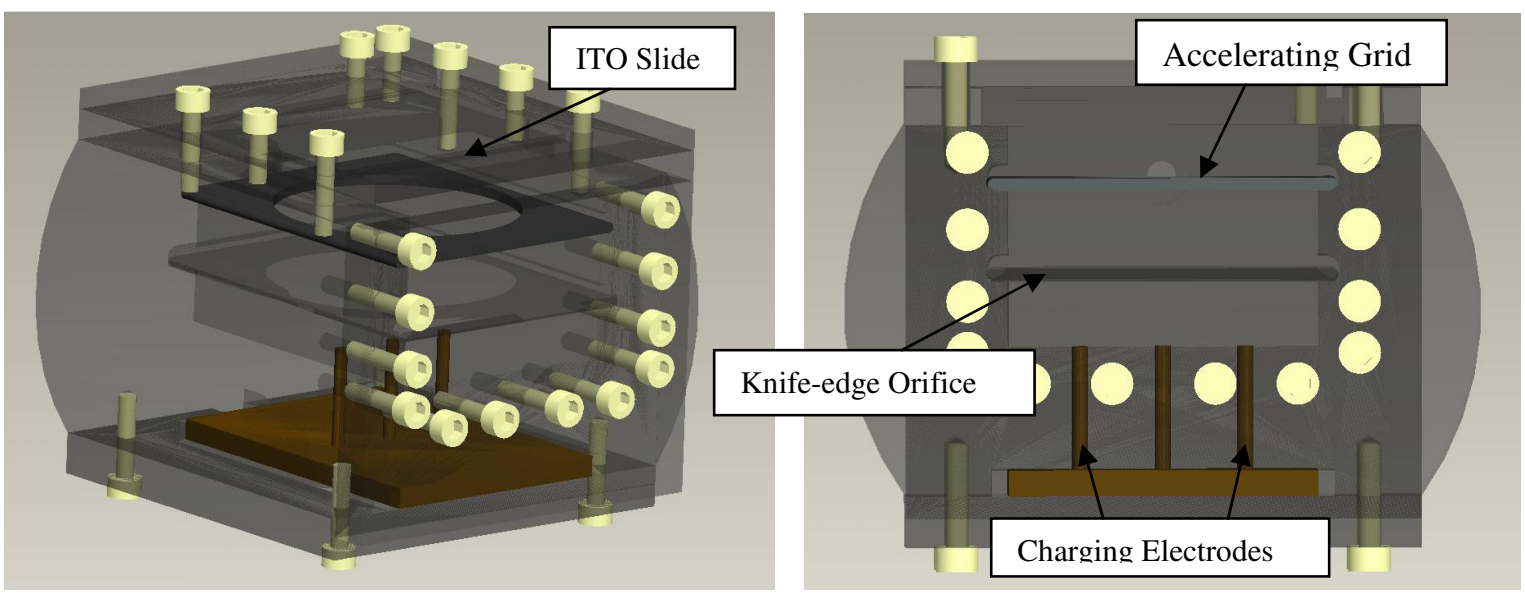

Figure 7. Particle extraction test cell design. Isometric (left) and side (right) views of the particle extraction cell are shown to depict all major components of the test cell. Each particle in the test cell is placed on top of one of the high-aspect ratio charging electrodes and is extracted through the accelerating grid.

These different configurations allowed for observing the impact that different knife-edge orifice arrangements would have on particle extraction. In flight, all configurations were successful at extracting particles. Figure 8 shows one of the particle extraction cells used for flight.

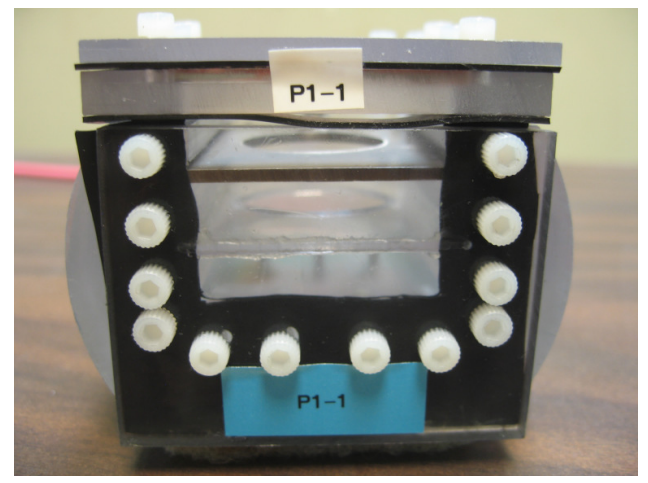

Figure 8. Front view of a large single orifice particle extraction cell. The charging electrodes in the cell were given a negative voltage bias while the steel accelerating grid in the middle and ITO slide at the top were connected to ground to extract particles.

The other type of test cell fabricated by the structures team was the liquid instability test cell. The requirements of the experiment dictated that each test cell should hold a specified amount of liquid, contain two parallel electrodes, and survive an applied voltage of $30 \mathrm{kV}$. Polycarbonate was used instead of the more readily available acrylic due to NASA safety regulations. Additionally, the experiment depended upon visual analysis, thus each test unit required a viewing window. A problem with polycarbonate is that it loses transparency when machined. To overcome this issue, the design process evolved into each test cell being composed of multiple polycarbonate pieces assembled with plastic screws and rubber gaskets to prevent leaking. The parallel electrodes run the length of the liquid filled channel and are the only electrically conductive pieces involved with the exception of the attached voltage supply lines. Figure 9 depicts an exploded view of the liquid instability test cell design. 


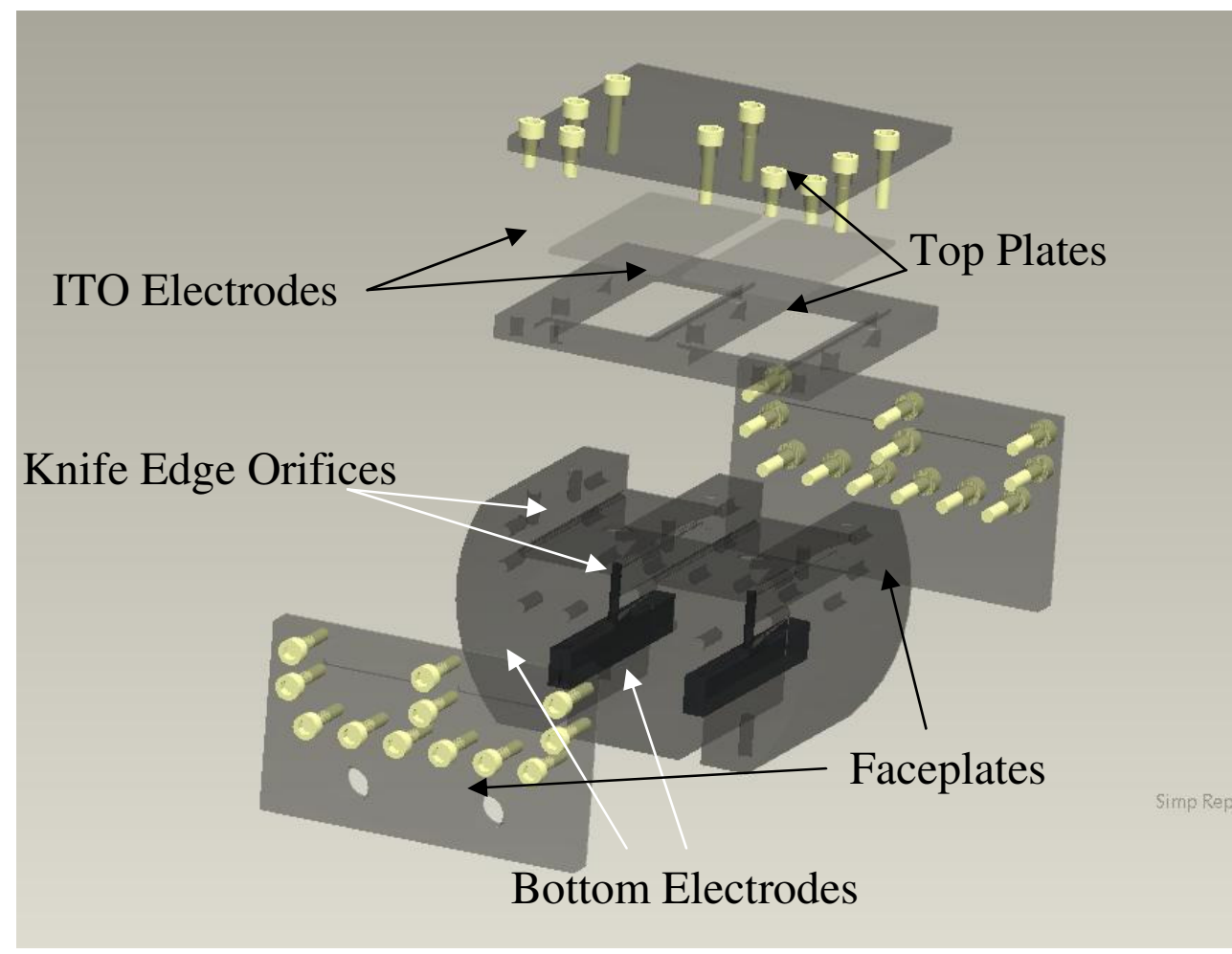

Figure 9. Exploded view of liquid instability test cell. All parts of liquid instability cell shown with the exception of the gaskets providing leak protection which fit between the top plates and ITO electrodes and between the faceplates and main body of the test cell.

All of the test cell pieces were designed and machined in-house as the design produced different prototypes as seen in Figure 10. The multiple prototypes tested different electrode and gasket configurations as well as the general manufacturing methods used later for full-scale production. As with the particle extraction test cells, knife-edge orifices were also used to keep the liquid within the liquid instability cell reservoirs during microgravity flight.



Figure 10. Instability prototype test cell progression. First prototype (top left) exposed several leak problems in the design, which were improved upon in the second revised cell prototype (top right). The final prototype dual and single channel instability cells (bottom). 
Aside from the experiment test cells, the structures team fabricated the structural pieces for a high-voltage switching device, referred to as the pin-switch mechanism. The device is made up of several components to create an array of 13 switches housed inside a polycarbonate container. Inside the polycarbonate box, there is a single copper electrode plate that spans across all switches and leads to the high-voltage power supply. Below this plate, there are 13 individual electrodes that act as contacts to provide a path to a specific test cell channel. When a switch is activated, a conductive pin is engaged so that it contacts both the common high-voltage plate and the individual plate for the cell being tested. High-voltage from the high-voltage power supply is then transferred through the activated pin to the test cell channel. The de-activation sequence of the pin-switch mechanism is seen in Figure 11, showing that no hot-switching in the presence of high-voltage is required. For activation of the switch, the process is simply reversed.

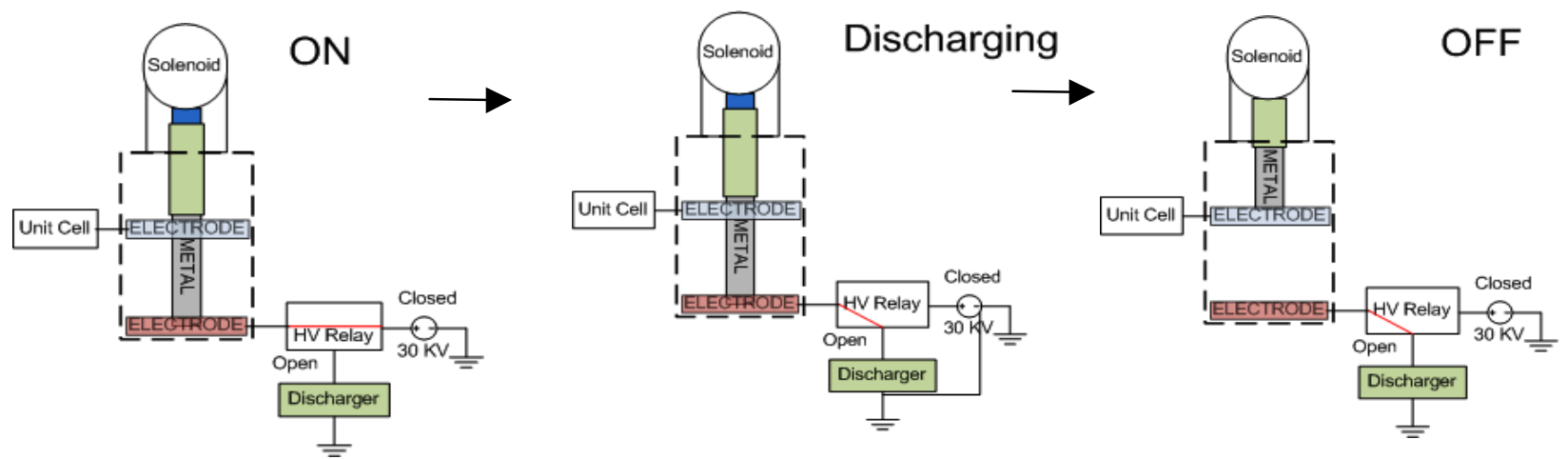

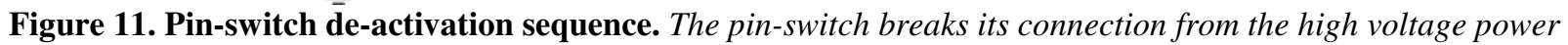
supply and connects all test cells to a discharger. This ensures full discharge of the system before any test is started.

Two prototype iterations of the pin-switch mechanism were first implemented before fabricating the final array. The first prototype created was a single cell that mainly provided a visual of the mechanism concept. A more developed second prototype was then built as seen in Figure 12.

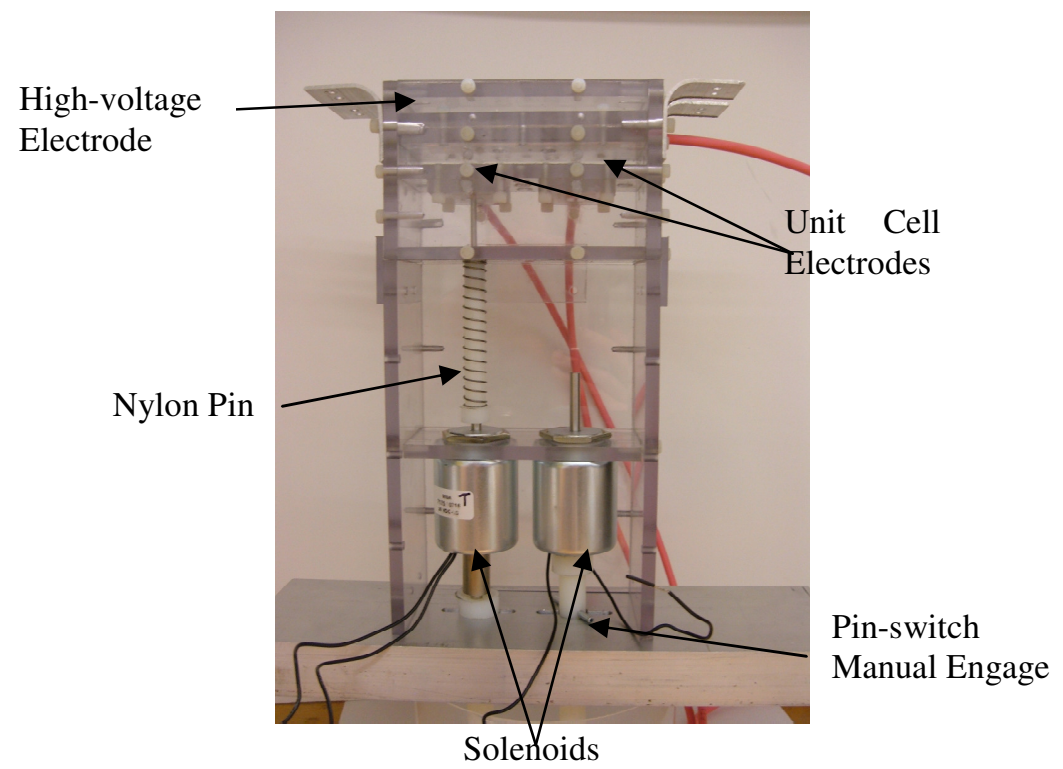

Figure 12. Pin-switch prototype concept. The second prototype of the pin-switch mechanism could be engaged by either the experiment automation system or manually its left switch is currently engaged

This version was functional tested to ensure the concept would work before the full 13-cell array was constructed. The two pin-switch prototypes implemented epoxy potting inside the polycarbonate box housing the electrodes. It was initially believed that this would be a safer system since it would insulate the electrodes. However, 
during functional testing, electrical arcing occurred at high-voltages due to metal burrs inside the switch created during the fabrication process. In order to fully remove all the burrs along with sharp edges where electric fields tended to focus, the final pin-switch mechanism did not include any epoxy potting. Also, the final prototype and full flight array included manual pins for engaging and disengaging the pin-switch in the event of a control system failure.

The last part of the fabrication process for the structures subsystem was the construction of the experiment chassis. The experimental chassis's fundamental function is to securely hold all of the necessary equipment required for the C-9 NanoBLUE experiment while remaining in compliance with physical and electrical constraints. Due to the experiment being flown in a pressurized aircraft cabin and experiencing accelerations between 0 and 1.8 that of gravity, the chassis is required to withstand certain loads and accelerations. The limit accelerations, as well as the volume envelope and weight distribution are closely regulated by NASA and their Reduced Gravity Operations. For simplicity, the frame was constructed of Aluminum 6061 unistrut with steel brackets. This structure underwent moderate load analysis as discussed earlier (section II). The structures subsystem also tried to achieve ergonomic design of the chassis through proper equipment placement in order to aid the flight crew while they experienced a range of gravitational accelerations. Ergonomic considerations included placement of experiment control mechanisms to prevent difficult or awkward reaching in flight and convenient placement of instruments to help ensure the flight crew did not become spatially disoriented in flight by the need to constantly turn their heads to make various readings. Since safety was a primary concern, padding was added to all sharp edges and side paneling applied to ensure the flyers and equipment were protected.

A major issue dealt with while constructing this experiment was maintaining cleanliness within all flight hardware. During acceptance testing, the introduction of even small amounts of particulate contamination into test cells was seen to drastically change the behavior of the liquid once subjected to electric fields and could result in unplanned grounding paths in the test cells. Therefore, a set of established procedures was followed to maintain cleanliness in all flight hardware. First, gloves were to be always worn while cleaning and running ground tests to avoid contamination. Second, before and after testing, all test elements were cleaned off with Kimwipes, water, and isopropanol. Also, the test area was cleaned and all objects not involved with ground testing removed from the area to ensure safety around the high-voltage experiments. Lastly, all team members involved with testing were instructed to leave the test cell covered when not cleaning or refilling the cell as this was seen to be the easiest way to reduce the level of contamination.

\section{B. Power and Electrical Systems}

The power and electrical subsystem was responsible for creating all electrical connections in the experiment. This included wiring the test cells, pin-switch mechanism, power supplies, and the high-voltage distribution box. The high-voltage box further shielded the flight crew from high-voltage connections and components. The box was made of polycarbonate containing the discharger, high-voltage relay, and high-voltage probe as depicted in Figure 13. The high-voltage probe stepped down the voltage by a factor of 1000 so that it could be easily monitored with a handheld multimeter. When the "On" position is activated, the connection was established between the test cell interface and the high-voltage source. The "Off" position was used to discharge the test cells. The discharger was a $100 \mathrm{M} \Omega$ resistor, which is the exact design that was tested and proven in the previous year's flight to discharge the stored power in a test cell within milliseconds.

The high-voltage distribution system was tested under simulated test conditions with a high-voltage power supply before integrating it in with the rest of the experiment structure. Furthermore, individual components of this system were also tested for functionality and durability under cases such as unexpected discharges of the system and emergency shut downs during testing.

The power and electrical system was also responsible for creating a method of keeping all of the experiment wiring orderly in the experiment structure. This was achieved by creating wire harnesses with zip-ties to tie several different low voltage lines together. However, this method also had the downside of allowing for cross-talk between different control signal lines if certain wires were not shielded properly from one another. This is discussed further in the ground testing section of section III. 


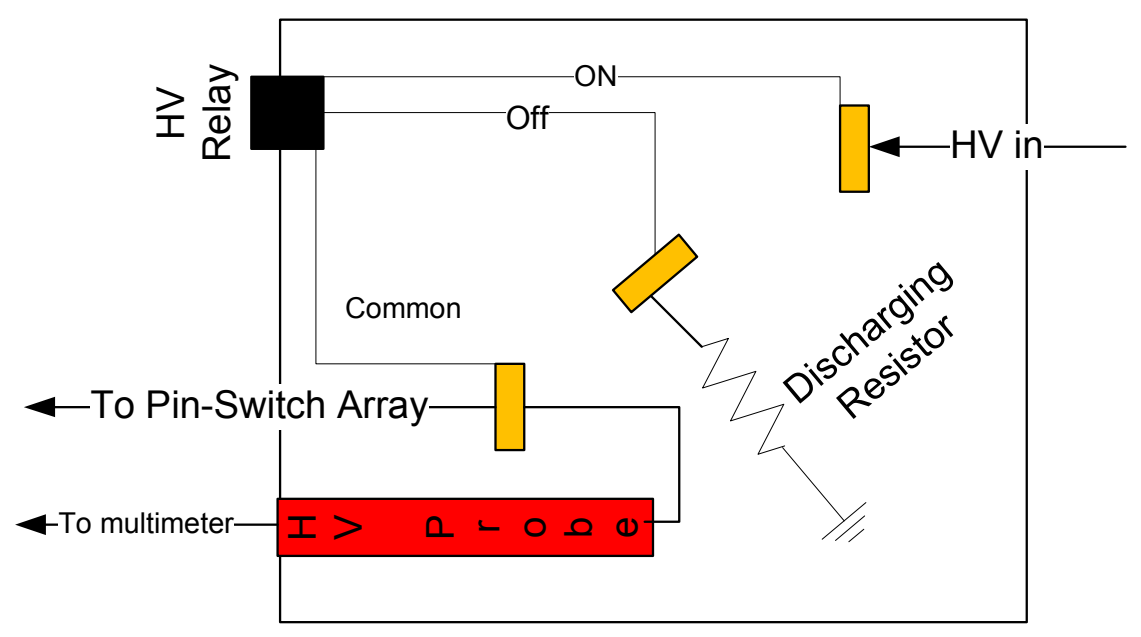

Figure 13. High-voltage distribution box. The box also served as a point in the experiment that could be grounded manually in the event of an emergency. The high voltage $(H V)$ relay was controlled by the low-voltage power source to bring the relay into an "on" position to connect the pin-switch mechanism and the high voltage power supply.

\section{Automation Code/ Data Capture Systems}

A LabVIEW program was created to automate the experiment, freeing members of the flight crew to focus on the experiment results and to troubleshoot problems more effectively. The program was created to control the output voltage signals in the control circuits and to control experiment data acquisition. This program communicated with a Keithley 2400 sourcemeter and a Keithley 3102 DAQ. The sourcemeter controlled the output of the high-voltage supply, which was ramped linearly between a user specified start voltage and end voltage with a specified ramp increment. To ensure that the experiment took advantage of the full microgravity period, the user could also input the amount of time the experiment would take. The user had the option of manually lowering the voltage and pausing the voltage ramp while the experiment was running. The graphical user interface (GUI) used to run this automation program is shown in Figure 14.

Data acquisition was achieved through the Keithley 3102 DAQ. The DAQ measured the output voltage of the Keithley 2400, the output voltage of the Glassman high-voltage power supply, the output current of the Glassman, the three-axis accelerometer data from the aircraft, and the voltage from the experiment's manual trigger switch. The data was saved to a text file as it was read. The LabVIEW program would search for a filename that was not already being used at the beginning of each iteration, ensuring that no files were overwritten. After being acquired by the DAQ, the data had to be synchronized with the camera videos for post-test processing.

To synchronize the data with the camera videos, the trigger switch and LEDs placed in the view of the camera were used. When the user flipped the switch to turn on the pin-switch mechanism, the user also pushed the trigger button simultaneously. The trigger button would send a timestamp to the computer while the switch would turn on the corresponding LED to the cell being tested. This would provide a common reference point between the data recorded by the DAQ and the video data from the front and top-view cameras.

A MATLAB code was written to take the text files from the data capture system as an input and analyze the data for the time when trigger switch was hit during the experiment. The MATLAB code would then output the times when the trigger was pressed and the corresponding voltages of the Glassman high voltage supply and the Keithley sourcemeter controlling the output of the Glassman. These numbers could then be easily compared with the flight video to what events captured by the camera matched up with these trigger times. 


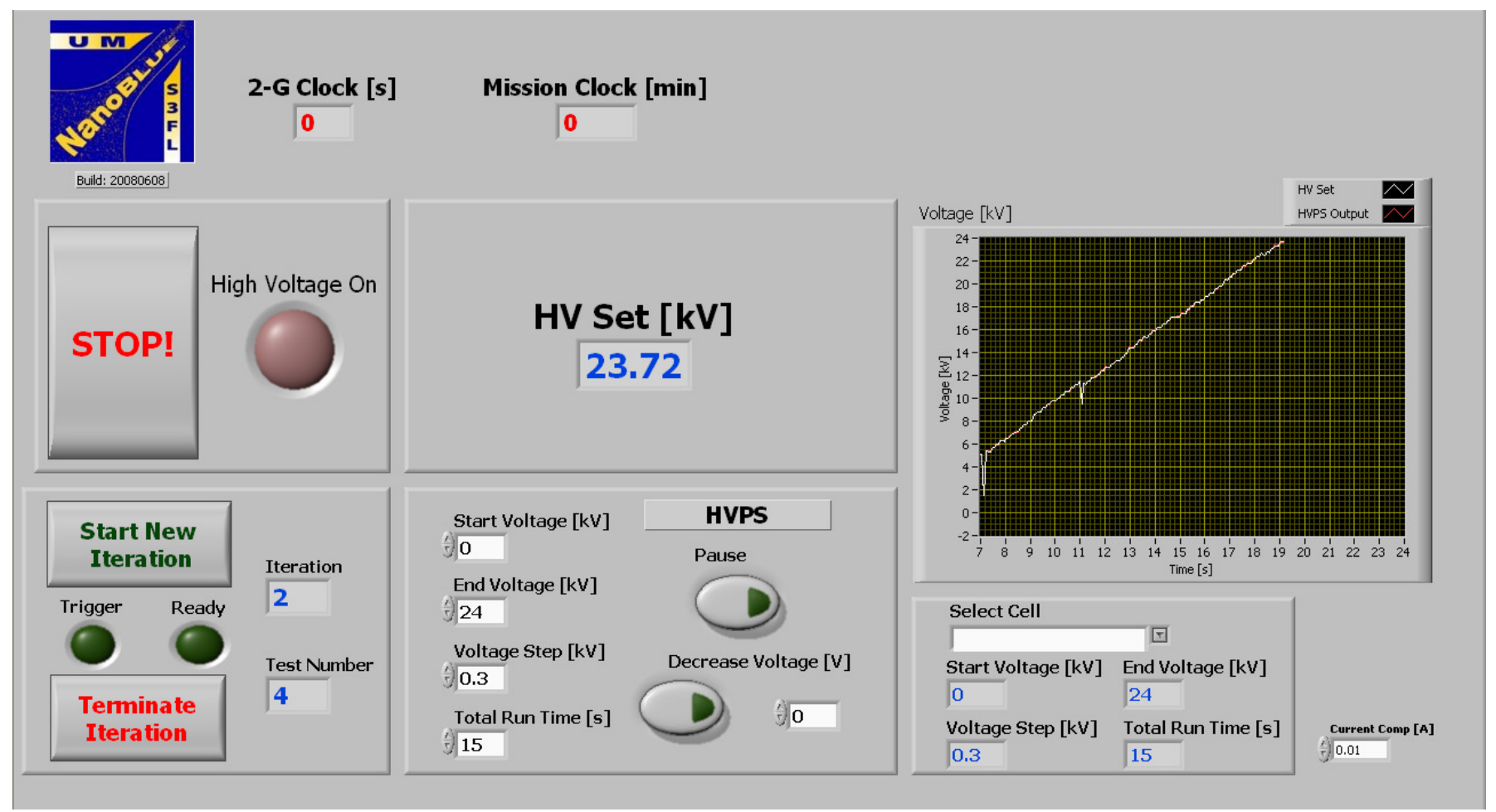

Figure 14. Experiment automation graphical user interface. This was used as the computer interface for running the integrated experiment tests on the ground and in flight.

\section{Camera Systems}

The camera system consisted of two cameras observing the experiment and one field camera observing the flight crew and overall experiment structure. The two experiment cameras were used to view the test cells. These cameras were placed on a translating camera track and connected by a brace so that they could be moved along at the same distance. The first camera was facing the front plate of each unit cell and the second was positioned to view down through the cell from the top. LEDs along the test cell tracks indicated when the switch was activated, therefore allowing the team to synchronize timestamps in each video. The forward facing camera model was a Sony Handicam DVD 505. It had the ability to capture $3 \mathrm{~s}$ of high speed footage at $240 \mathrm{fps}$, which used to capture particle dynamics as particle extraction events tended to occur on time scales not visible to the naked eye. The top view camera was recording continuously during the flight. It ultimately provided some of the most useful video for Taylor cone formation confirmation. The field view camera captured the test conditions of the experiment and the interactions of the flyers for post-flight analysis. This was useful to later show any problems for the flight crew in conducting the experiment or any varying light conditions occurring around the experiment.

In the previous year's flight, lighting was an issue, so for this test the camera was tested in many different lighting scenarios on the ground to find the best lighting scheme in the structure. The results showed that a florescent lamp provided the right lighting conditions to gain the best picture possible. More light was needed when the front camera's high-speed mode was run because the increase in frames per second caused a decrease in camera resolution.

\section{E. Ground Testing}

The C-9 NanoBLUE ground testing campaign began as soon as the first prototype test cells were fabricated by the structures team. These tests evolved during the design process until a standard procedure was established that was subsequently used to qualify the flight hardware produced before it was integrated into the experiment structure. These testing procedures developed on the ground then served to drive the development of the microgravity testing procedures. Analysis of ground test videos not only helped build quantitative data to build theories for flight performance, but they also allowed for analysis on the effectiveness of lighting on the test cell, the locations of where Taylor cones were likely to form, and particle dynamics through the use of a MATLAB analysis code developed within the team. Ultimately, through the extensive improvement and standardization of ground test 
procedures, the 2007-2008 C-9 NanoBLUE team was able to see large improvements in useful data from the microgravity flight.

In order to qualify each test cell for flight, all electrical connections were first checked for continuity or to assure an open circuit where expected. A handheld multimeter with attached probes was used for all checks. For instability unit cells, this included continuity checks between the electrodes (top and bottom) and their attached wires. The particle extraction cells required a similar continuity check procedure. As continuity, or an open circuit, was verified, the resistance indicated by the multimeter was recorded.

All test cells were tested at least once in a pressure bell jar at approximately 1.5 times the pressure difference that would be seen when the cells were taken aboard the pressurized aircraft. The cells were left at this pressure for two hours, the duration time of the flight, and checked at the end of the test for leaks through visual inspection and massing the cell to compare with the pre-test mass. If leaks were found, the cell would be adjusted, refilled, and tested again. This process was repeated for each cell until all had passed the leak test.

Liquid instability cells were tested individually on the ground to test their ability to form Taylor cones before being integrated into the flight experiment chassis. Each cell was tested by attaching its electrodes to a high-voltage power supply and slowly ramping up the voltage until a Taylor cone was observed and recorded by a video camera or the voltage limit was reached. This safety limit for the electric field was set at $2.3 \mathrm{~V} / \mu \mathrm{m}$ to limit occurrence of electrical arcing due to air breakdown. The voltage was then noted and the video saved to later review the location of Taylor cone formation and its characteristic dynamics in the ground test.

Once continuity was verified on the particle extraction cells, acceptance testing took place to ensure that particle extraction could take place on the ground within the test cell. The cells first underwent a test with no liquid. A voltage of $21 \mathrm{kV}$ was initially applied to the cell and held for a few seconds. The cell was simply observed to ensure no electrical arcing occurred and that all particles extracted. In the event that this was not the case, modifications were made and the cell was re-tested under the same conditions. The cell was next tested with a silicone oil reservoir to verify no leaking would occur above the knife edge orifice or out of the system. Alignment modifications to the grids and knife-edges were made during acceptance testing as necessary.

Acceptance testing of the automation code was completed by running the entire experiment through the sequence of tests that were planned for flight. Acceptance testing of the data acquisition system was done at the same time as the testing of the automation code. During acceptance testing, significant electrical noise was observed in the system. Shielding was added in both the wires and around the high-voltage power supply to reduce noise in the data acquisition system to an acceptable level. Low-voltage wires were put into twisted pair configurations to also aid in reducing system noise.

\section{F. Flight Operations Dry Runs and Contingency Simulations}

Prior to flight, several integrated systems tests were run to verify functionality of all equipment with the experiment automation software. These tests were used to step through the flight sequence and make any adjustments or improvements before flight. Setup for each test included initializing all equipment, filling each cell to the appropriate liquid level, placing particles in the extraction cells, and connecting all the necessary wires. Once the cameras were focused and aligned, the automation program was initialized to begin testing of the particle extraction cells. For particle extraction tests, the operator activated the high-speed mode on the front camera to record particle extraction once they were observed to lift off.

As part of the integrated systems testing, the experiment flight crew underwent two full flight operational dry runs. The first was a nominal test, which was run similarly to how it would be executed during flight. This included using pre-flight and post-flight check lists, making the appropriate announcements to the experiment camera during tests, and changing electrical connections for different test cells at designated times. The second round of dry run testing was an off-nominal run in which the flyers were given problems to solve that could occur during flight. To do this, the two flyers would run through the experiment on the ground just as they would in flight. However, in the background, another team member would occasionally call out a scenario. Even though the problem was not actually occurring, the flyers that were practicing had to change their operation to correct the error just as they would during flight.

To prepare flyers for possible in-flight problems, a contingencies list was created. This list contained any problem that could interrupt normal experimental operation during flight. Examples of contingencies include a flyer becoming sick due to microgravity, software failures, or a high-voltage cable disconnecting from a unit cell during flight. Both ground and flight crew members had to individually determine the proper course of action for each contingency. Once all team members had completed this contingency quiz, the best answers were chosen and both flight and ground crew were expected to review them. The contingencies list proved useful, as some of the problems did occur during flight and were resolved effectively. 


\section{Flight Operations}

During flight week, the last adjustments were made to the experiment and the experiment was presented to the NASA safety officials. As a final measure to ensure reliable data was taken, the experiment was strategically positioned on the aircraft cabin as far as possible from other experiments that could potentially introduce extra electromagnetic interference into our experimental measurements. The experiment also proved robust to sickness of the flight crew as members became sick during flight at different times, but the experiment goals could still be completed by one flight crew member.

For flight, a predefined order of the various tests was created to ensure maximum data collection. During each flight, particle extraction tests were tested first, followed by liquid instability test cells with decreasing knife-edge orifice sizes. The flight test matrix can be seen in Appendix A. Pre-made test sheets were created for the flight crew running the experiment to be able to take notes regarding test results and testing conditions. Furthermore, check lists were created for pre-flight and post-flight to ensure proper handling of all test equipment. Lastly, the first flight crew was meant to brief the second flight crew before their flight, and the data from the first flight was meant to be analyzed in between the two scheduled flight days so alterations to the experiment setup or test plan could be made if necessary. However, due to a delay in the schedule during flight week, both flights took place on the same day, and only a short briefing between the two flight teams was possible. Fortunately, this was enough time for the information to be passed on between the teams as the experiment had no apparent faults during flight.

\section{A. Experimental Results}

Detailed results of the experiments can be found in a companion paper. ${ }^{8}$ Both the flight and ground test data show good agreement with their respective theoretical models. The liquid surface instabilities were observed to be more difficult to excite in circular orifices as the diameter decreases. Particle extraction from both air- and liquidfilled test cells was successfully demonstrated in a microgravity environment. The results from the NanoBLUE project provided useful test data to support further development for NanoFET. A summary of achieved objectives can be seen in Table 1.

\section{Objective}

Flight Testing Ground Testing

Obtain data on electric field threshold for liquid instability in normal gravity.

Obtain particle extraction data in normal gravity.

Develop and demonstrate experiment automation system.

Determine variations in NanoFET caused by different knife-edge geometries.

Determine electric field threshold for liquid instability in microgravity.

Demonstrate millimeter-size particle extraction in microgravity.

Table 1. Summary of NanoBLUE completed objectives. Team NanoBLUE has successfully completed its ground and flight objectives for its 2007-2008 experiment showing good support the methods of S3FL, the high utility of the NASA Reduced Gravity Student Flight Opportunities Program and for the further development of NanoFET technologies.

\section{B. Problems Encountered and Corrective Actions Taken In Flight}

During flight, the most commonly occurring problem was electrical arcing within the test cells at the highest applied test voltages. The standard procedure for dealing with arcing was to first terminate the automation code and then switch off the high-voltage relay connection. Another problem encountered in flight was run-time errors in the LabVIEW code. Typically, these errors were caused by improper termination of the program. Another issue encountered with the particle extraction cells was that a few of the particles during the second flight, which used liquid-filled particle test cells, became dislodged from their charging posts during flight due to vibrations on the aircraft causing liquid movement in the cell. Some liquid was also seen to have sloshed over the knife-edges in the cells due to the forces imparted on it during the C-9 aircraft take-off. This was mainly a problem however in the larger knife-edge orifices and ended up not impacting the test results (Reference AIAA-2008-5096). Despite the problems encountered in flight, the team was well prepared to handle them due to rehearsal of test plans and study of test contingencies prior to flight.

A problem noticed in the post-flight analysis was that the trigger meant to place a timestamp in the flight data where points of interest occurred was not always pressed correctly. This problem occurred because flyer reaction 
times were not always in-sync with the video camera recording system. Another issue dealt with on a continual basis in both ground testing, flight testing, and post-flight analysis is the background noise on the data lines. In testing, this was treated by shielding low-voltage and high-voltage wires as well as shielding the major sources of electromagnetic interference (EMI) such as power supplies and meters. In post-flight analysis, this was handled by averaging data to smooth out voltage spikes and by searching for the trigger signal, which was at a higher voltage than almost all of the background noise seen in ground testing and in flight.

\section{Education and Outreach}

Undergraduates involved in the C-9 NanoBLUE project are privileged to several educational benefits. Team members learn how to work together within subsystems and communicate effectively on a larger project. The students on this team have been exposed to hands-on research, analysis, and laboratory skills useful for working in the aerospace industry and other technical areas. Furthermore, the design documents and design reviews required by this project helped develop technical communications that will become important in whatever future careers team members have. Lastly, select students were given the opportunity to fly on the C-9 aircraft in which they experienced microgravity while conducting research, a rare and inspiring experience. The results of this program show several benefits to its participants and lend tangible proof to the benefits of participation within S3FL and the C-9 Reduced Gravity Student Flight Opportunities Program.

An important part of the C-9 project experience is sharing knowledge with other students. Several outreach events were conducted to teach local K-12 students various aerospace and systems engineering concepts as well as to show the benefits of an education within technical fields. At these outreach events, both individual and group communication skills were discussed to show the different interaction skills required to be successful as an engineer today. These workshops were well received by both the students and the various parents that came along as chaperones helping to build a positive reputation for team NanoBLUE, S3FL, and the University of Michigan. The goodwill created by these events will be further built upon in years to come as more outreach events are organized through S3FL each year.

\section{Conclusions and Future Work}

During both flights, data collection was a success. The number of operations was manageable by the flight crew present, and all problems encountered in flight were handled successfully. Data was ultimately collected on each test cell flown and brought back for post-flight analysis. Furthermore, the experiment served to fulfill the objectives of S3FL. Through working on team NanoBLUE, undergraduate engineering students were trained to use a systems engineering approach to real engineering design problems in space applications. This project taught several different engineering skills to its team members with different software analysis programs such as ProEngineer, COMSOL, and MATLAB, and the project also gave team members valuable lab experience in machining, electrical prototyping, and experiment design. Lastly, team NanoBLUE was able to hold various outreach events for local K12 students to inspire a new generation of engineers and scientists. The C-9 NanoBLUE team can be considered a success for S3FL, and its team model will continue to be used and further developed in future projects within the lab.

\section{A. Evaluation of team technical systems development}

The technical systems of the NanoBLUE experiment were greatly improved over last year's flight. While many of the same components were used, automation code was used along with the pin-switch mechanism to forego any extra human interaction with the experiment in flight. The experiment was simpler to operate and redundant systems allowed data to be accurately captured. One issue that arose during integrated systems testing was that there was a significant amount of noise on the data lines due to coupling between power supplies. While this problem was not fully fixed, the team was able to smooth the data and extract accurate measurements.

\section{B. Evaluation of team personnel management}

The NanoBLUE team this year had its own successes and failures in the management of the 15-person team. To accommodate the large number of team members, the team was broken up into five separate subsystems: systems, structures, payload, power and electrical/ command and data handling, and business/ outreach. The implementation of these subsystems allowed the management of a smaller number of personnel under the leads of each subsystem who in turn were managed by the team lead. The incorporation of subsystems into the NanoBLUE team could be considered a success in personnel management. 
This setup, though, had some shortcomings. In certain cases, team members were not comfortable addressing issues with their direct subsystem lead, and thus the problems were taken directly to the team lead, creating a gap within team communication. In the future, creating more trust within the team will hopefully address this, as well as help the subsystem leads to learn what kind of personality they need to connect with different team members. Another drawback to this method of personnel management is that the team lead was not very closely involved with the details of each subsystem. Meetings between the team lead and subsystem team leads were implemented to mitigate this problem.

\section{Future work for C-9 NanoBLUE and S3FL with microgravity program}

Future work for the C-9 NanoBLUE team will include investigation into an alternate design concept of NanoFET. Rather than using liquid to transport the nanoparticles, piezoelectric devices may be used to move the particles in a non-liquid environment. NanoBLUE may investigate the feasibility of using these devices in the microgravity environment in future flight opportunities.

\section{Appendix A: Flight Test Matrix}

\begin{tabular}{|c|c|c|c|c|c|c|c|c|c|c|}
\hline DAY 1 & \# Cells & Liquid & Particles? & $\begin{array}{l}\text { Orifice } \\
\text { Geometry }\end{array}$ & $\begin{array}{c}\text { Orifice } \\
\text { Width/ } \\
\text { Diameter } \\
\text { [mm] }\end{array}$ & $\begin{array}{l}\text { \# Channels } \\
\text { Per Cell }\end{array}$ & \# Tests & $\begin{array}{l}\text { Unit Cell } \\
\text { Volume [fl } \\
\quad \text { oz] }\end{array}$ & $\begin{array}{c}\text { Total } \\
\text { Volume [fl } \\
\text { oz] }\end{array}$ & Notes \\
\hline L10 & 1 & Soybean oil & No & Circular & 10 & 2 & 2 & 0.454 & 0.454 & Negative control experiment \\
\hline L15 & 2 & Soybean oil & No & Circular & 15 & 2 & 4 & 0.454 & 0.908 & Baseline \\
\hline L20 & 1 & Soybean oil & No & Circular & 20 & 2 & 2 & 0.454 & 0.454 & \\
\hline L30 & 1 & Soybean oil & No & Circular & 30 & 1 & 1 & 0.567 & 0.567 & \\
\hline L40 & 1 & Soybean oil & No & Circular & 40 & 1 & 1 & 0.567 & 0.567 & \\
\hline $\mathbf{s}$ & 1 & Soybean oil & No & Slot & $10 \& 15$ & 2 & 2 & 0.454 & 0.454 & Differently sized orifice for each channel \\
\hline P1 & 1 & Air & Yes & Circular & 25.4 & 1 & 1 & - & - & \\
\hline P3 & 1 & Air & Yes & Circular & 7.9 & 1 & 1 & - & - & \\
\hline \multirow[t]{2}{*}{ PS } & 1 & Air & Yes & Slot & 7.9 & 1 & 1 & - & - & \\
\hline & 10 & & & & & & 15 & & 3.404 & Totals for flight day \\
\hline
\end{tabular}

\begin{tabular}{|c|c|c|c|c|c|c|c|c|c|c|}
\hline DAY 2 & \# Cells & Liquid & Particles? & $\begin{array}{l}\text { Orifice } \\
\text { Geometry }\end{array}$ & $\begin{array}{c}\text { Orifice } \\
\text { Width/ } \\
\text { Diameter } \\
\text { [mm] }\end{array}$ & $\begin{array}{c}\text { \# Channels } \\
\text { Per Cell }\end{array}$ & \# Tests & $\begin{array}{l}\text { Unit Cell } \\
\text { Volume [fl } \\
\text { oz] }\end{array}$ & $\begin{array}{c}\text { Total } \\
\text { Volume [fl } \\
\text { oz] }\end{array}$ & Notes \\
\hline L15 & 1 & Soybean oil & No & Circular & 15 & 2 & 2 & 0.454 & 0.454 & Baseline \\
\hline L20 & 2 & Soybean oil & No & Circular & 20 & 2 & 4 & 0.454 & 0.908 & \\
\hline L30 & 1 & Soybean oil & No & Circular & 30 & 1 & 1 & 0.567 & 0.567 & \\
\hline L40 & 1 & Soybean oil & No & Circular & 40 & 1 & 1 & 0.567 & 0.567 & \\
\hline S10 & 1 & Soybean oil & No & Slot & 10 & 2 & 2 & 0.454 & 0.454 & \\
\hline S15 & 1 & Soybean oil & No & Slot & 15 & 2 & 2 & 0.454 & 0.454 & \\
\hline P1 & 1 & Silicone oil & Yes & Circular & 25.4 & 1 & 1 & 0.439 & 0.439 & \\
\hline P3 & 1 & Silicone oil & Yes & Circular & 7.9 & 1 & 1 & 0.439 & 0.439 & \\
\hline \multirow[t]{2}{*}{ PS } & 1 & Silicone oil & Yes & Slot & 7.9 & 1 & 1 & 0.439 & 0.439 & \\
\hline & 10 & & & & & & 15 & & 4.721 & Totals for flight day \\
\hline
\end{tabular}

\section{Acknowledgments}

The NanoBLUE project was made possible by generous grants from the Michigan Space Grant Consortium and Women in Science and Engineering. Thanks to the C-9 NanoBLUE team members including John Bell, Matthew Putz, and Christopher Rossi and the S3FL Executive Committee for their hard work allowing this project to be possible. Special thanks to University of Michigan Aerospace Professor Peter Washabaugh, Dr. David Morris of ElectroDynamics Applications, Inc., Louis Musinski, a doctoral candidate within the University of Michigan Electrical Engineering and Computer Science department, and Michael Lee at the Wilson Student Team Project Center for their guidance and support over the past two years of this project. NanoBLUE would also like to thank the University of Michigan Plasmadynamics and Electric Propulsion Laboratory (PEPL) and University of Michigan Space Physics Research Laboratory (SPRL) for their support over the past year. The University of Michigan Aerospace Engineering technical staff (Thomas Griffin, David McLean, Chris Chartier, and Terry Larrow) and Dr. 
Christopher Deline (University of Michigan Electrical Engineering) were also of particular help during the project's fabrication phase. Finally, thanks to all the staff of the NASA Reduced Gravity Office for the two flight opportunities and their guidance and availability to answer questions along the way.

\section{References}

${ }^{1}$ Smetana, A., Liu, T., Lessack, S., Wind, R., et al., "Microgravity Flight Testing as a Case Study on the Student Space Systems Fabrication Laboratory," ASEE 2007-1442, 114th Annual ASEE Conference \& Exposition, Honolulu, HI, 24-27 June 2007.

${ }^{2}$ Sopensky, E., "Trying out zero gravity," Potentials, IEEE, vol.17, no.3, pp.38-41, Aug/Sep 1998

${ }^{3}$ Liu, T., Musinski, L., Patel, P., Gallimore, A., Gilchrist, B., and Keidar, M., "Nanoparticle Electric Propulsion for Space Exploration," in Space Technology and Applications International Forum - STAIF 2007, edited by M. S. El-Genk, American Institute of Physics, Albuquerque, NM, 2007, pp. 787-94.

${ }^{4}$ Suvorov, V. and Zubarev, N., "Formation of the Taylor cone on the surface of liquid metal in the presence of an electric field," J. Phys. D: Appl. Phys., 37 (2004), pp. 289-97.

${ }^{5}$ Musinski, L., Liu, T., Gilchrist, B. and Gallimore, A., "Nanoparticle Field Extraction Thruster (nanoFET): Introduction to, Analysis of, and Experimental Results from the "No Liquid" Design Option," AIAA-2008-5097, 44th AIAA/ASME/SAE/ASEE Joint Propulsion Conference, Hartford, CT, 21-23 July 2008.

${ }^{6}$ Liu, T., Musinski, L., Keidar, M., Gallimore, A., and Gilcrist, B., "Physical Models and Performance Implications for the Nanoparticle Field Extraction Thruster," IEPC-2007-186, 30th International Electric Propulsion Conference, Florence, Italy, 17-20 September 2007.

${ }^{7}$ Man, P., Mastrangelo, C., Burns, M., and Burke, D., "Microfabricated Capillarity-Driven Stop Valve and Sample Injector," in The Eleventh Annual International Workshop on Micro Electro Mechanical Systems (MEMS 98) Proceedings, IEEE, Heidelberg, Germany, 2008, pp. 45-50.

${ }^{8}$ Liu, T., Drenkow, B., Musinski, L., Gallimore, A., Gilchrist, B., Mirecki-Millunchick, J., Morris, D., Doan, A., Munski, J., and Muldoon, A., "Developmental Progress of the Nanoparticle Field Extraction Thruster," AIAA2008-5096, 44th AIAA/ASME/SAE/ASEE Joint Propulsion Conference, Hartford, CT, 21-23 July 2008. 